\title{
Modeling the Growth of Transportation Networks: A Comprehensive Review
}

\author{
Feng Xie · David Levinson
}

Published online: 18 October 2007

(C) Springer Science + Business Media, LLC 2007

\begin{abstract}
This paper reviews the progress that has been made over the last half-century in modeling and analyzing the growth of transportation networks. An overview of studies has been provided following five main streams: network growth in transport geography; traffic flow, transportation planning, and network growth; statistical analyses of network growth; economics of network growth; and network science. In recognition of the vast advances through decades in terms of exploring underlying growth mechanisms and developing effective network growth models, the authors also point out the challenges that are faced to model the complex process of transport development.
\end{abstract}

Keywords Transportation $\cdot$ Network growth $\cdot$ Modeling

\section{Introduction}

Ever since Euler (1736) introduced the first transportation network in a scientific sense in the classical problem of the seven bridges of Konigsberg, there has been a long-established interest for professionals and scholars in gaining a greater understanding of transport network systems and their temporal changes. The literature that discusses this subject has been prolific. Three comprehensive reviews, for example, came from Fullerton (1975), who introduced the development of British transport networks, Taaffe et al. (1996),

F. Xie $(\bowtie) \cdot$ D. Levinson

Civil Engineering, University of Minnesota, 500 Pillsbury Drive SE,

Minneapolis, 55455, USA

e-mail: xiex0055@umn.edu 
who outlined the evolution of the US transport systems, and Garrison and Levinson (2005), who examined transportation experience in the past centuries from the perspectives of transport policy, planning, and deployment.

Transport development represents a complex and dynamic process that involves a magnitude of dimensions, which may be topological (eg., addition and abandonment of linkages between places and facilities), morphological (eg., structural changes to infrastructure in shape and orientation), technical (eg., emerging modes, advances in pavement quality and intelligent technology), economic (eg., tax or toll, nationalization or privatization), managerial (eg., regulation, signal control, car-pooling), social (eg., pollution, congestion, sprawl, "highway mania"), or political (eg., jurisdiction, equity, funding allocation). Despite the fact that the growth of transportation networks is complicated and multidimensional, and the duration is usually measured in decades, it may still be tractable and predicable with a further understanding of the underlying mechanisms. Under this belief, sustained efforts have been put in the modeling and analysis of transportation networks in fields ranging from geography, regional science, economics, natural science, and urban planning, to transportation engineering.

Previous studies have followed five main streams. In the 1960s and 1970s, geographers viewed network growth as topological transformation, aiming to either extract the process of structural changes or replicate the emergent topologies of transportation networks; since the 1970s, the prevalence of travel demand forecasting models provides transportation planners and economists with an effective tool for predicting traffic flows on a network and modeling the optimal changes to the network, with the belief that network growth is the result of rational decisions by jurisdictions, property owners, and developers in response to market conditions and policy initiatives; recent largescale statistical analyses, aroused by the availability of sufficient data and increasing data processing ability, related the change of transportation supply (the presence or absence of infrastructure, service frequency or capacity, etc.) to the demographic and socio-economic characteristic of tributary areas, as well as traffic conditions and other attributes of infrastructure; the economics of network growth examines various economic dimensions of network growth, ranging from traditional transportation economics to public economics, network effect, path dependance, and coalition formation; since the 1990s when the new network science came into the scene, studies on the dynamics of complex systems have thrived. The concepts of preferential attachment or self-organization have been introduced to interpret network dynamics as a spontaneous process. Recently, a growing interest has been aroused by natural science in modeling the evolution of transportation networks using agentbased simulation to represent the initiatives and behaviors of independent agents and capture their interactions in a holistic process.

This paper aims to provide an overview of this substantial body of quantitative studies. The following five sections survey the five streams of studies respectively. The last section summarizes these studies in terms of their subjects, methods, and connection rules. 


\section{Transport geography}

Transportation networks are commonly simplified as graphs with elementary components retained: nodes indicate centroids of human settlements (places), facilities, and intersections of routes; links represent segments of infrastructure or service routes; flows represent the actual patterns of movement on networks. It was not until 1960 that Garrison and Marble (1962) introduced graph theory to the study of transportation networks in the literature of geography, regional science, and transportation studies (Lowe and Moryadas 1975).

During the economic geography/regional science movement in the 1960s and 1970s, a few studies were conducted by geographers to model the growth of transportation networks in terms of their structural transformation and topological changes. The most comprehensive outlines of these are found in Harggett and Chorley (1969) and in Lowe and Moryadas (1975).

Attempts have been made to model the continuous growth of transportation networks in a series of discrete stages. Taaffe et al. (1963) proposed a fourstage model as illustrated in Fig. 1 to describe the process of road network development when colonial exploitation proceeds from the coastal baseline to the inland area in an underdeveloped country. Pred (1966) applied the Taaffe model to Atlantic seaboard of the USA, while Rimmer (1967) applied the model to the South Island of New Zealand. Lachene (1965) developed a staged model of network development on a hypothetical isotropic transport network. The model starts with a network of dirt trails and a more or less uniform distribution of economic activity. As towns form at some intersections, a road network is built to link these settlements. While some trails become paved roads, some less used links are abandoned in the countryside when economic activities concentrate in the urban centers. Finally a superior network, perhaps a railroad or a freeway, emerges connecting the urban centers.

In another strand of studies, rather than describing network growth in stages, researchers constructed models that would replicate observed

(a)

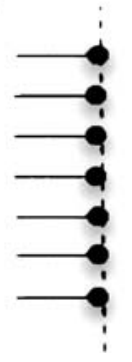

(b)

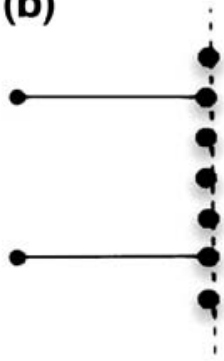

(c)

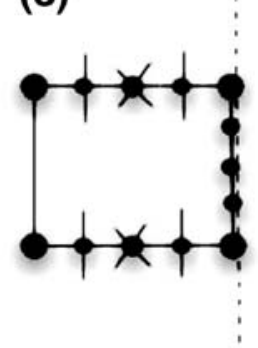

(d)

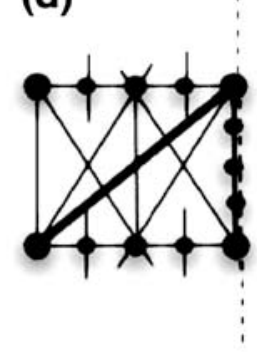

Fig. 1 An illustration of the four-stage model of network growth from costal line: (a) scattered ports with equally small size are located along the coast of a colonial region; (b) then penetration lines are built from interior to reach selected ports; (c) connected ports then develop because of the growth of inland trading, as well as the inland feeders; and (d) as more links are built to interconnect developed nodes, links are also differentiated and important links emerge 
developed network patterns. Garrison and Marble (1962) described their attempts to simulate the changing topology of the Northern Ireland railroad system between 1830 and 1930 using Monte Carlo methods, while Morrill (1965) reported parallel studies on the rail networks of central Sweden. Kansky (1969) developed a quantitative predictive model of network structure and applied it to the Sicilian railroad. He selected 16 settlements in Sicily which by 1908 would have been on the railroad network in a random process among 30 major settlements in this region. The first link is added to connect the two largest centers and then links are gradually added such that the next largest center joined the largest and closet center in the network. Kolars and Malin (1970) modeled the development of the Turkish railroad network employing an approach different from node connection. They propose transportation links emerge on major ridge lines as defined by a population-accessibility surface. Black (1971) conceived of the railroad network in Maine as a tree branching out from Portland, growing outward to connect outlying peripheral nodes. The possibility of constructing a link is calculated as a function of potential revenue, construction cost, with a constraint of the angle of the link. The presence or absence of a link between a pair of vertices at a particular time is determined by whether the score exceeds a threshold.

However, these studies, aroused by the interest to replicate the observation of network topologies, had to deal with simple networks using heuristic and intuitive rules for network growth and transformation, due to the lack of understanding on the inherent mechanisms with regard to why and how transportation networks evolve. Based on a review of these contemporary studies, Harggett and Chorley (1969) pointed out that they are "somewhat fragmentary", and that a "general theory of network growth lies in future research". The study of the temporal development of transportation networks remained largely dormant for the following thirty years.

\section{Optimization and network design}

Traffic flow plays an essential role in driving network growth. As Lachene (1965) indicates, road capacity which exceeds the traffic at the time when road are built results in a low marginal cost to the provision of additional transportation services, which may lead to differentiations of nodes and links as a network evolves. Newell (1980) and Vaughan (1987) examined traffic flows in shaping various network geometries. It was the prevalence of travel demand forecasting models (Sheffi 1985; de Dios Ortuzar and Willumsen 2001) that made it possible to forecast travel demand on networks in a realistic way, and led to the marked revival of the interest on modeling the evolution of transportation networks.

In recent years, solution algorithms to user equilibrium have been widely incorporated to solve the network design problems (NDP). Typically the NDP is formulated as a bi-level framework in which the lower-level represents the demand-performance equilibrium for given investment while the upper 
level represents the investment decision-making of the transport planner to maximize social welfare based on the unique equilibrium flow pattern obtained from the lower-level problem (LeBlanc 1975; Yang and Bell 1998). A continuous NDP problem deals with the optimal capacity expansion of existing links while a discrete NDP derives the design of an optimum amount of transportation supply by changing the actual topology of the network, that is, by adding or removing links. In practice, the set of potential investments may be from a limited set.

If the NDP were how decisions are made, network changes would be due to planners' rational behaviors to maximize the efficiency of a given network, measured according to some quantifiable objective, based on predicted traffic with budget and other constraints. However, more factors come into play in reality. Curry (1964) claimed that while every locational decision may be optimal from a particular point of view, the resulting actions as a whole may appear to be random. Because of spatial lock-in, transportation networks may have a locational stability which is greater than the individual components making up these networks. From the perspective of transportation economics, Zhang and Levinson (2005) pointed out NDP simplifies a network growth problem in three aspects: investment decisions are considered independent of pricing rules and ownership structures; only the optimal investment rule is considered; and inter-dependencies of sequential decisions are ignored. Bertolini (2007), observing that conventional planning approaches do not adequately account for the irreducible uncertainty of future developments, proposed an evolutionary approach of urban transportation planning addressing how individual decisions and actions could eventually accumulate into development processes which are both path dependent and unpredictable.

\section{Empirical models of network growth}

Although statistical analysis has been widely used in regional science and transportation studies, it found limited application in analyzing the growth of transportation networks, largely due to the scarcity of historical data in the past. Only recently, with the availability of sufficient data and increasing data processing ability, especially powered by GIS technology, a widespread interest has been seen to investigate the temporal change of transportation supply in statistical analyses based on historical observations.

Early work by Gaudry (1975) and Alperovich et al. (1977) employed simultaneous equations to examine the mutual causality of transit demand and supply. Extending their research, Peng et al. (1997) developed a simultaneous route-level transit ridership model and estimated the model using the data from the Tri-County Metropolitan Transportation District of Oregon (Tri-Met) service area. The results indicate that simultaneity exists between transit demand and supply, especially the service supplied is influenced by the past ridership and current demand. Taylor and Miller (2003), on the other hand, accounted for the simultaneity between transit demand and supply 
using a two-stage least squared (2SLS) regression method. Levinson (2007) examined the mutual causality between the changes that occurred in the rail network and density of population in London. With panel data representing the 33 boroughs of London over each decade from 1871 to 2001, models were estimated using the panel corrected standard errors procedure and the results disclosed the spatial co-development of rail networks and population in London.

Mohammed et al. (2006a) modeled the temporal change in transit supply explicitly. In their attempt to model the changes that occurred over a 15-year period in the bus network of the City of Missisauga, Toronto, they employed multiple regression and simultaneous equation models to relate transit supply (measured by bus frequency) to a group of demographic, socioeconomic, and route-specific variables. In a subsequent study, they further introduced artificial intelligence to understand the behavior of transit agencies and simulate the growth of transit routes (Mohammed et al. 2006b).

Statistical analyses have also been applied in recent years to examine the temporal change of road supply. Cervero and Hansen (2002) employed a simultaneous equations system to estimate both vehicle miles traveled and lane miles of supply, suggesting that the relationship is two way (based on Granger causality tests) and that similar forces are at work affecting changes in both travel demand and infrastructure supply. At a microscopic level, Levinson and Karamalaputi (2003a,b) examined in two parallel studies the expansion and new construction of a network, respectively, based on the present conditions of the network, traffic demand, demographic characteristics, project costs, and a budget constraint. Binary logit (and mixed logit) models are used to associate the expansion and new construction of each link with historic data including physical attributes of the network, their expansion and construction history and AADT values on each of the links. Levinson and Chen (2007) developed an area-based model of highway growth; binary logit models were adopted to estimate the new route growth probability of divided highways and secondary highways using high-quality GIS data of land-use, population distribution, and highway network for the Twin Cities Metropolitan Area from 1958 to 1990. Levinson and Chen (2005) employed a Markov chain model to analyze the spatial co-evolution of transportation and land use for the Twin Cities Metropolitan Area from 1958 to 1990. A transition matrix records the interaction between transportation and land use and is used to predict the future development of transportation and land use.

\section{Economics of network growth}

From a microscopic perspective, transportation economists have shown a widespread interest in network pricing, ownership structures, and capacity investment (Gomez-Ibanez et al. 1999). Due to computational complexity, they typically adopt a theoretical framework in network modeling and base 
the analysis on small hypothetical networks. For example, Verhoef and Rouwendal (2004) explored the interrelations between pricing, capacity choice, and financing in a small network model; Zhang and Levinson (2005) proposed an analytic model which discusses properties of long-run network equilibrium with regard to price and capacity with different small network layouts and ownership regimes.

From a macroscopic perspective, it has been observed by Taaffe et al. (1996) that the development of all modes of transport has been affected by a constantly shifting mix of laissez-faire economics stressing private enterprise, on the one hand, and government initiatives at local, state, and national levels, on the other hand. The trade-off between centralized versus decentralized provision of general public goods has been a classic problem examined in public economics and political science (Oates 1972; Besley and Coate 2003). Centralized provision of transport infrastructure involves a single unitary government that is responsible for the financing, investment, maintenance, and operation of transport networks (e.g. roads), while a decentralized pattern involves autonomous local jurisdictions that build networks (roads) individually, or in coalitions, to connect to each other.

In theory, a wide literature of financial federalism has treated the issues related to jurisdictional provision of public goods, among which some examined the political economy of transportation infrastructure provision in particular (Barankay 2004; Kopp 2006). In practice, Knight (2002) discusses the federal grants and crowd-out state-government spending for the Federal Highway Aid Program employing a political model. Humplick and Moini-Araghi (1996a,b) presented their cross-country studies of road decentralization. Only limited efforts, however, have been put to model the impact of jurisdictional control in shaping network growth. Levinson et al. (2007) incorporated jurisdictional planning processes to forecast network growth. In their attempts to predict the Twin-Cities seven-county road network 30 years from now, they developed network forecasting models with stated decision rules, processes encoded in flowcharts and weights developed from official documents or by discussion with agency staff. As shown by Montes de Oca and Levinson (2006), different levels of jurisdictions including the state (the Minnesota DOT), region (the Metropolitan Council), and seven counties developed respective stated decision making (investment) processes in which federal or local funding are allocated to road projects prioritized according to their funding needs based on measured pavement quality, level of service, safety, and other conditions. Xie and Levinson (2007a) explored in a simulation environment how a road network is deployed differently under centralized versus decentralized jurisdictional control.

In addition, there are issues such as network effects, path dependence, and collation formation that have been examined extensively in the economic literature, and revealed to be essential to network growth, but none of them has, to our knowledge, been modeled formally in a way that affects network growth endogenously. The following provides a brief survey of these dimensions in turn. 


\subsection{Network effects}

The seminal paper "The Economics of Networks" by Economides (1996) opened the way to examine a salient collective property of network industries, called alternatively a network externality or network effect. The network effect has been defined as a change in the benefit, or surplus, that an agent derives from a good when the number of other agents consuming the same kind of good changes. Since this type of side effect is known as an externality in economics, externalities arising from network effects are known as network externalities. Positive network effects are obvious as one's value increases from others using the same product, while negative network effects also exist, especially where there are resource limits, such as on the overloaded freeway or crowded bandwidth. Shapiro and Varian (1998) illustrates network externalities using a simple demand and supply model. Their model predicts a typical process of network growth under network effect: the number of users connected to the network connected to the network is initially small, and increases only gradually as costs fall. When a critical mass is reached, the network growth takes off dramatically.

Network externalities have played a fundamental role in driving network dynamics in many network industries such as telecommunications, financial exchanges, software, and the Internet. Transportation, as a network industry, is no exception. When a new place or facility with residents and businesses is connected to a transportation network, the residents and businesses at other already connected places benefit from the new connection because they now enjoy accessibility to more activities. Evidence of network effects in transportation networks has been provided by studying the history of transportation networks. Nakicenovic (1998), by plotting a large number of curves for transportation systems, showed that S-curves fit the temporal realization of transportation networks very well. As suggested by the S-surves, there is a long period of birthing as the network is researched and developed, there is a growth phase as the network is deployed, and a slower mature phase as the network has occupied available market niches. For instance, the US highway network expanded very slowly from 1860 to 1920 and from then on started an exponential climb, before slowing again at the end of the twentieth century. These observations coincide with the prediction of Shapiro and Varian's model subject to network effect. No theoretical or empirical studies, however, have been found to model and evaluate network effects during the growth of transportation networks.

\subsection{Path dependence}

Where we are today is a result of what has happened in the past, thus the current conditions of a system have a sensitive dependence on its initial conditions, which is referred to as "path dependence" (Arthur 1994). Liebowitz and Margolis (1995) pointed out where information is imperfect, a certain form of path dependence may lead to lock-ins and market failure 
that are regrettable but costly to change, even in a world characterized by independent decisions and individually maximizing behavior. Despite an increasing realization that transport development is a sequential process which clearly does not follow a socially optimal design, due to the lack of information when local or individual "optimal" decisions are made (Bertolini 2007; Zhang and Levinson 2005), how and to what extent imperfect information and path dependence could affect network growth remain unclear to scholars.

\subsection{Coalition and network formation}

How groups form and are organized to conduct political, economic, and social activities are subjects of intense game-theoretic research (Demange and Wooders 2005). The seminal work by Jackson and Wolinsky (1996) aroused a new stream of contributions using networks (graphs) to model the formation of links among individuals. Marini (2007) provides an overview of recent developments in the theory of coalition and network formation for economic applications. These advances in economic theory also shed new light on the research of network growth. As transport infrastructure may be provided by multiple local jurisdictions and (or) private firms, the growth (or decline) of a transportation network is usually involved with the interplay of jurisdictional or economic oligopolies, although their interactions are subject to spatial constraints. This can be observed in the Interurban network of Indiana in 1910, constructed and operated by more than 20 private firms (Hilton and Due 1960), and in the historical Virginia State Route 267, consisting of three sections (two toll roads of the Dulles Toll Road and Dulles Greenway and a free road for Dulles Airport access) that are operated by Virginia Department of Transportation, a private company, and the Metropolitan Washington Airports Authority, respectively. How the jurisdictional or industrial organization of strategic players (providers and operators) subject to spatial constraints shapes a network is another interesting subject that deserves academic examination.

\section{Network science}

Traditionally, physicists modeled the dynamics of a transportation network as an optimization process, with a particular focus on extracting the aggregate features of the network with simplified cost functions. Schweitzer et al. (1998) investigated the evolution of road networks during the optimization process by which a minimized travel detour is compromised with a minimized cost of constructing and maintaining roads. Gastner and Newman (2006) presented an optimization model to minimize the cost of building and maintaining a network. Optimized network structures were able to replicate certain qualitative features of the networks. Barthélemy and Flammini (2006) proposed a model of traffic networks via an optimization principle in which the topology of the optimal network turns out to be a spanning tree and, by changing model parameters, different classes of trees are recovered. 
Since the 1990s, as Barabási (2002) claimed in his book Linked: The New Science of Networks, a new science has emerged based on new findings on complex networks. A unique power-law distribution has been observed in a variety of so-called "scale-free" networks, such as the World Wide Web, citation networks, metabolic networks, and the network of human sexual contacts (Albert et al. 1999; de Solla Price 1965; Jeong et al. 2000; Liljeros et al. 2001). Newman (2003) presented a comprehensive review of these findings. In exploring how scale-free networks emerge and evolve, Barabási and Albert (1999) found that as new nodes enter a scale-free network, they are more likely to link to highly connected nodes than lesser connected nodes, and this feedback loop gives preference to the large nodes. He called this process "preferential attachment", which has been intensively studied to explain the dynamics of complex networks (Jeong et al. 2000; Barabási 2002; Dorogovtsev and Mendes 2002).

As the physics community became interested in surface transportation networks, however, it was recognized that they exhibit attributes that differ from scale free networks (Csányi and Szendröi 2004; Gastner and Newman 2006; Jiang and Claramunt 2004; Lämmer et al. 2006), largely due to the spatial constraints in a surface transportation network that limit the number of connections from a node to its neighbors. Although this "rich get richer" growth mechanism of preferential attachment seems not to apply to most transportation systems perfectly, it provides some insight to transportation studies: First, preferential attachment may explain the emergence of hub-andspoke systems that widely exist in non-geographical transportation networks such as airline networks. Second, when independent nodes link to a network, they tend to connect to established and more important nodes, although the importance of a node is not necessarily associated with the number of connections as it is in a scale-free network, and the direct connection may be realigned to reduce cost and avoid competition between redundant routes. Third, large-scale order and organization may emerge based on independent decisions as a network grows, which has been extensively examined in another emerging scientific field, self-organization.

Self-organization exists in many complex systems that seem spontaneously to evolve into large-scale order, even based on simple behaviors of independent agents in the systems (Schelling 1978; Krugman 1996). Since the late 1990s this concept has been introduced to interpret the evolution of various complex networks ranging from the Internet, social networks, to biological networks employing agent-based simulation (Newman 2003).

Agent-based simulation also found applications to interpret the dynamics of transportation networks. Lam and Pochy (1993) and Lam (1995) proposed an active-walker model (AWM) to describe the dynamics of a landscape, in which walkers as agents moving on a landscape change the landscape according to some rule and update the landscape at every time step. Helbing et al. (1997) adopted the active walker model to simulate the emergence of trails in urban green spaces shaped by pedestrian motion. In this process, pedestrians directly walked to their respective destinations on a homogenous 
ground at the beginning. Then frequently used trails got reinforced since they are chosen by pedestrians more while rarely used trails withered and were finally destroyed. Consequently, the trails bundled and emerged into different patterns. Helbing et al. (1997) found out that their model was "able to reproduce many of the observed large-scale spatial features of trail systems." Yamins et al. (2003) present a simulation of road growing dynamics on a land use lattice that generates global features as beltways and star patterns observed in urban transportation infrastructure. However, their simulation did not consider the dynamics of traffic flows. Zhang and Levinson (2004) examined the growth of a real-world congesting network the Twin Cities road network with autonomous links. Based on the network topology in 1978, simulation experiments were carried out to predict road expansions in twenty years, and the predicted 1998 network is compared to the real one. Yerra and Levinson (2005) and Levinson and Yerra (2006) demonstrated that a road network can differentiate into an organized hierarchical structure from either a random or a uniform state, suggesting that the hierarchy of roads, rather than necessarily being designed by planners or engineers, is an emergent property of network dynamics. Xie and Levinson (2007c) developed an evolutionary model of network degeneration based on the posited weakest link heuristic, which incorporates individual links as autonomous agents that operate on their own, while the weakest member in the network is shuttered in an iterative process. This model was then employed, in a broader context, to examine the topological evolution of surface transportation networks (Xie and Levinson 2007b), essentially simulating an underdeveloped area where all point-topoint paths can be used, with those paths which are more valuable reinforced while least used ones abandoned as the network evolves, thereby enabling a variable network topology forming from a bottom-up process. The weakest link heuristic originates from the greedy algorithm (Cormen et al. 1990), in which locally optimum choices are made in a discrete optimization process at each stage with the hope of finding the global optimum. Empirical evidence has been found that even based on myopic and local optimum decisions, the simulation model replicated well the course of link abandonment in the Interurban network of Indiana (Xie 2007), and that of link deployment in the skyway network of downtown Minneapolis (Corbett et al. 2007).

\section{Summary}

The temporal development of transport systems including inland waterways, turnpikes, rails, airlines, and roads over the last two centuries is complicated and multidimensional. Our interest in this review is the modeling and analysis of the growth of transportation networks. Sustained efforts over the last halfcentury have been put to model network growth in a broad set of fields including physics, geography, economics, natural science, urban planning, and transportation engineering, and not surprisingly, generated a wide literature 
that varies in subject, method, and growth mechanism. Table 1 summarizes a selection of these studies in chronological order for an overview.

As can be seen, geographers in the early days had to limit their modeling efforts to heuristic and intuitive connection rules that allow them to replicate the observations of structural changes in networks, due to the lack of understanding of underlying growth mechanisms. It was not until the introduction of travel demand modeling and formal models of user equilibrium that researchers were able to predict traffic flow across a network in a systematic way, thereby solving the "optimal" changes in transport supply that minimize user cost on the network under budgetary constraints. Since then the concept of a bilevel optimal network design has dominated consideration of the evolution of networks within urban transportation planning.

In contrast to the static, one-dimensional environment in which optimal network designs were solved, economics reveal a more complex world. In reality, transport development has been the outcome of decisions that are made from independent economic and political initiatives. Factors such as interplay between strategic players, and organization of individual players in coalitions with monopoly power may significantly affect the course of network growth. Transport development also demonstrates characteristics such as network effects and path dependence due to externalities and incomplete information that arise from an evolutionary process. These dimensions, however, have not been formally treated in network growth models. Time-series statistical analyses that relate the changes in transport supply to various demographic, economic, and technic factors based on historical observation provide some insights, although they are costly and largely case-specific. Thus it remains a big challenge for researchers and practitioners to develop a systematic evolutionary approach of transportation planning in which transport development could be modeled in a more realistic way and transport supply could be provided more effectively.

Recent scientific advances in modeling complex systems and complex networks provide new opportunities. Tremendous interests have been aroused to interpret the growth of transportation networks adopting the concepts of preferential attachment and self-organization from natural science. Agent-based simulation has provided an effective tool by which independent initiatives, behavioral rules, and travel demand forecasting could be integrated in a holistic process, and has seen widespread applications in network growth models. One caveat is that due to the complexity of the issue examined, most agentbased simulations were only able to include simple and myopic objectives or behavioral rules of agents. Obviously more sophisticated behaviors could be realized at the cost of adding more complexity to the model. At which point the trade-off between realisticity and complexity should be made remains an open question. Additionally, most of these models have been exploratory, including theoretical work presented without validation and empirical models validated only on some basic aggregate features (e.g. connection patterns) or the rough sequence of line deployment or abandonment. Is this evidence sufficient to support a model of such a complex process? How far can we go with these 


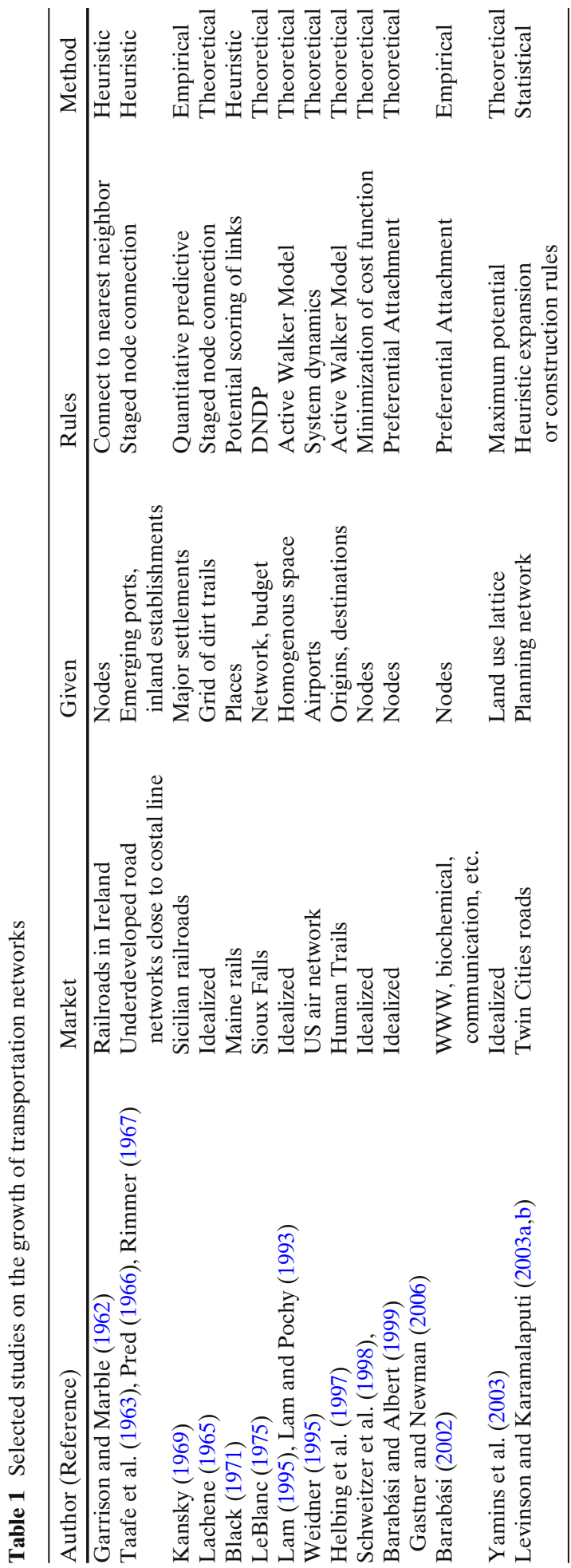




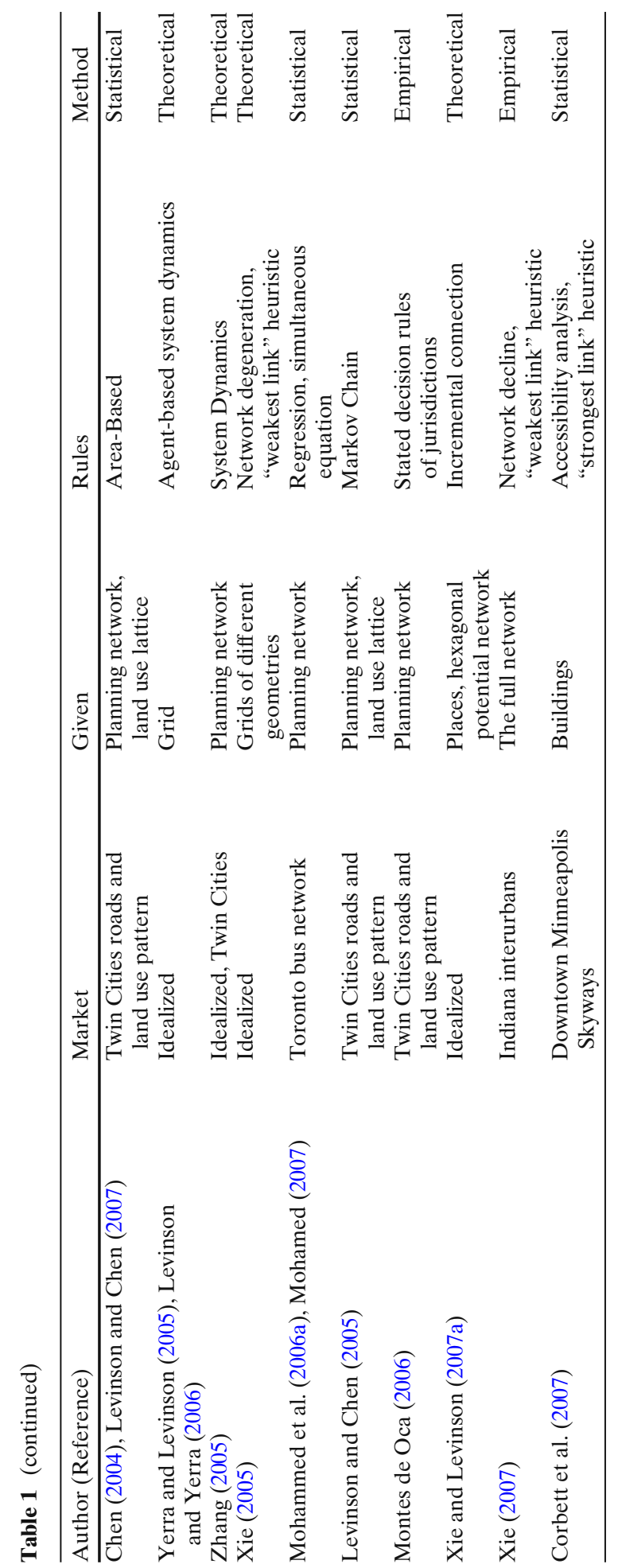


network growth models to predict the future, or at least provide insightful implications for transportation planning? These are also questions that deserve further investigation.

\section{References}

Albert R, Jeong H, Barabási AL (1999) Diameter of the world-wide web. Nature 401:130-131

Alperovich G, Kemp M, Goodman K (1977) An econometric model of bus transit demand and supply. The Urban Institute Working Paper No. 5032-1-4, Washington, DC

Arthur WB (1994) Increasing returns and path dependence in the economy. University of Michigan Press, Ann Arbor, Michigan

Barabási A (2002) Linked: the new science of networks. Perseus Publication

Barabási AL, Albert R (1999) Emergence of scaling in random networks. Science 286:509-512

Barankay I (2004) The political economy of transport decentralisation. Technical report, ECMT Round Table 130

Barthélemy M, Flammini A (2006) Optimal traffic networks. J Stat Mech p L07002

Bertolini L (2007) Evolutionary urban transportation planning: an exploration. Environ Plann A 39:1998-2019

Besley T, Coate S (2003) Central versus local provision of public goods: a political economy analysis. J Public Econ 87(4):2611-2637

Black W (1971) An iterative model for generating transportation networks. Geogr Anal 3:283-288

Cervero R, Hansen M (2002) Induced travel demand and induced road investment: a simultaneous equation analysis. J Transp Econ Policy 36:469-490, LSE and the University of Bath

Chen W (2004) Highway network evolution models. Master's thesis, University of Minnesota at Twin Cities

Corbett M, Xie F, Levinson D (2007) Evolution of the second-story city: the Minneapolis Skyway System. Presented at World Conference on Transportation Research Society (WCTRS) in Berkley, July 2007

Cormen TH, Leiserson CE, Rivest RL, Stein C (1990) Introduction to algorithms. The MIT Press, Chapter 17, p 329

Csányi G, Szendröi B (2004) Fractal-small-world dichotomy in real-world networks. Phys Rev E 70

Curry L (1964) The random spatial economy: an exploration in settlement theory. Ann Assoc Am Geogr 54:138-146

de Dios Ortuzar J, Willumsen LG (2001) Modeling transport. Wiley

de Solla Price DJ (1965) Networks of scientific papers. Science 149:510-515

Demange G, Wooders M (2005) Group formation in economics: networks, clubs and coalitions. Cambridge Univ. Press

Dorogovtsev SN, Mendes JFF (2002) Evolution of networks. Adv Phys 51:1079

Economides N (1996) The economics of networks. Int J Ind Organ 14(6):673-699

Euler L (1736) Solutio problematis ad geometriam situs pertinentis. Comment Acad Sci U Petrop 8:128-140

Fullerton B (1975) The development of British transport networks. Oxford Univ. Press

Garrison WL, Marble DF (1962) The structure of transportation networks. Technical report

Garrison W, Levinson D (2005) The transportation experience: policy, planning, and deployment. Oxford Univ. Press, USA

Gastner MT, Newman MEJ (2006) The spatial structure of networks. Eur Phys J B 49:247-252

Gaudry M (1975) An aggregate time-series analysis of urban transit demand: the Montreal case. Transp Res 9:249-258

Gomez-Ibanez J, Tye WB, Winston C (1999) Essays in transportation economics and policy. The Brookings Institution, Washington, DC

Harggett P, Chorley JC (1969) Network analysis in geography. Butler and Tanner

Helbing D, Keltsch J, Molnár P (1997) Modeling the evolution of human trail systems. Nature 388:47

Hilton GW, Due JF (1960) The electric interurban railways in America. Stanford Univ. Press, Stanford 
Humplick F, Moini-Araghi A (1996a) Decentralized structures for providing roads: a crosscountry comparison. Policy Research Working Paper 1658. World Bank, Policy Research Department, Washington, DC

Humplick F, Moini-Araghi A (1996b) Is there an optimal structure for decentralized provision of roads? Policy Research Working Paper 1657. World Bank, Policy Research Department, Washington, DC

Jackson M, Wolinsky A (1996) A strategic model of social and economic networks. J Econ Theory 71:44-74

Jeong H, Gombor B, Albert R, Oltwai ZN, Barabasi AL (2000) The large-scale organization of metabolic networks. Nature 407:651-654

Jiang B, Claramunt C (2004) Topological analysis of urban street networks. Environ Plann E 31:151-162

Kansky K (1969) Structure of transportation networks: relationships between network geometry and regional characteristics. Univ. of Chicago Press, Chicago

Knight B (2002) Endogenous federal grants and crowd-out of state government spending: theory and evidence from the federal highway aid program. Am Econ Rev 92(1):71-92

Kolars JF, Malin HJ (1970) Population and accessibility: an analysis of Turkish railroads. Geogr Rev 60:229-246

Kopp A (2006) The political economy of transport infrastructure funds. Center for Network Industries and Infrastructure (CNI) Working Paper No. 2006-10

Krugman PR (1996) The self-organizing economy. Blackwell

Lachene R (1965) Networks and the location of economic activities. Pap Reg Sci Assoc 14:183-196

Lam L (1995) Active walker model walker models for complex systems. Chaos, Solitons Fractals 6:267-285

Lam L, Pochy R (1993) Active-walker models: growth and form in nonequilibrium systems. Comput Simul 7:534

Lämmer S, Gehlsen B, Helbing D (2006) Scaling laws in the spatial structure of urban road networks. Physica A 363:89-95

LeBlanc LJ (1975) An algorithm for the discrete network design problem. Transp Sci 9(3):183-199

Levinson D (2007) Density and dispersion: The co-development of land use and rail in london. Networks, Economics \& Urban Systems (NEXUS) working paper

Levinson D, Chen W (2005) Paving new ground: a Markov chain model of the change in transportation networks and land use. In: Levinson D, Krizek K (eds) Access to destinations. Elsevier Publishers

Levinson D, Chen W (2007) Area-based models of highway growth. ASCE J Urban Plann Dev (in press)

Levinson D, Karamalaputi R (2003a) Induced supply: a model of highway network expansion at the microscopic level. J Transp Econ Policy 37:297-318

Levinson D, Karamalaputi R (2003b) Predicting the construction of new highway links. J Transp Stat 6:81-89

Levinson D, Xie F, de Oca NM (2007) Forecasting and evaluating network growth. University of Calgary, Van Horne Institute, Van Horne Institute

Levinson D, Yerra B (2006) Self organization of surface transportation networks. Transp Sci 40:179-188

Liebowitz SJ, Margolis SE (1995) Path dependence, lock-in and history. J Law Econ Organ 11:205-226

Liljeros F, Edling CR, Amaral LAN, Stanley HE, Aberg Y (2001) The web of human sexual contacts. Nature 411:907-908

Lowe J, Moryadas S (1975) The geography of movement. Houghton Mifflin Company

Marini MA (2007) An overview of coalition \& network formation models for economic applications. Working Paper Series in Economics, Mathematics, and Statistics 2007/12

Mohamed A (2007) Forecasting transit network evolution. PhD thesis, University of Toronto

Mohammed A, Shalaby A, Mille E (2006a) Empirical analysis of transit network evolution: case study of Mississauga, Ontario, Canada, bus network. Transp Res Rec 1971:51-58

Mohammed A, Shalaby A, Mille E (2006b) Modeling the supply of public transit: using artificial intelligence to model the evolution of the bus transit network. Working paper

Montes de Oca N (2006) Beyond business as usual: ensuring the network we want is the network we get. Master's thesis. University of Minnesota at Twin Cities 
Montes de Oca N, Levinson D (2006) Network expansion decision-making in the twin cities. Transp Res Rec 1981:1-11

Morrill (1965) Migration and the growth of urban settlement. Lund Stud Geogr Series B Human Geogr 26:65-82

Nakicenovic N (1998) Dyanmics and replacement of U.S. transport infrastructure. In: Cities and their vital systems-infratructure, past, present and future. National Academy Press, Washington DC

Newell GF (1980) Traffic flow on transportation networks. MIT Press, Cambridge

Newman M (2003) The structure and function of complex networks. SIAM Rev 45:167-256

Oates WE (1972) Fiscal federalism. Harcourt Brace Jovanovich, New York

Peng Z, Dueker KJ, Strathman J, Hopper J (1997) A simultaneous route-level transit patronage model: demand, supply, and inter-route relationship. Transportation 24:159-181

Pred A (1966) The spatial dynamics of U.S. urban-industrial growth. The MIT Press, Cambridge, pp 1900-1914

Rimmer P (1967) The changing status of New Zealand seaports. Ann Assoc Am Geogr 57:88-100

Schelling TC (1978) Micromotives and macrobehavior. Norton, New York

Schweitzer F, Ebeling F, Rose H, Weiss O (1998) Optimization of road networks using evolutionary strategies. Evol Comput 419-438

Shapiro C, Varian HR (1998) Information rules: a strategic guide to the network econom. Harvard Business School Press

Sheffi Y (1985) Urban transportation networks: equilibrium analysis with mathematical programming methods. Prentice-Hall, Englewood Cliffs, NJ

Taaffe E, Gauthier H, O'Kelly M (1996) Geography of transportation

Taaffe E, Morrill RL, Gould PR (1963) Transportation expansion in underdeveloped countries: a comparative analysis. Geogr Rev 53:503-529

Taylor BD, Miller D (2003) Analyzing the determinants of transit ridership using a two-stage least squares regression on a national sample of urbanized areas, Research Report Number 682, University of California Transportation Center, Berkeley

Vaughan R (1987) Urban Spatial Traffic Patterns. Pion Ltd, London

Verhoef E, Rouwendal J (2004) Pricing, capacity choice, and financing in transportation networks. J Reg Sci 44(3):405-435

Weidner T (1995) Hub equilibrium in the USA airnet. Master's thesis, University of California at Berkeley

Xie F (2005) The evolution of road networks: A simulation study based on network degeneration. Master's thesis, University of Minnesota at Twin Cities

Xie F (2007) Validation of the model of network degeneration: a case study of the Indiana interurban network. To be presented at 54th Annual North American Meetings of the Regional Science Council (NARSC) in Savannah November 2007

Xie F, Levinson D (2007a) Jurisdictional controls and network growth. Presented at World Conference on Transportation Research Society (WCTRS) in Berkley July 2007

Xie F, Levinson D (2007b) The topological evolution of road networks. Presented at transportation research board (TRB) in Washington, DC, January 2007

Xie F, Levinson D (2007c) The weakest link: a model of the decline of surface transportation networks. Transp Res Part E (in press)

Yamins D, Rasmussen S, Fogel D (2003) Growing urban roads. Netwo Spatial Econ 3:69-85

Yang H, Bell MGH (1998) Models and algorithms for road network design: a review and some new developments. Trans Rev 18:257-278

Yerra B, Levinson D (2005) The emergence of hierarchy in transportation networks. Ann Reg Sci 39:541-553

Zhang L (2005) A simulator of network growth for network economics and policy analysis. Master's thesis, University of Minnesota at Twin Cities

Zhang L, Levinson D (2004) A model of the rise and fall of roads. Presented March 2004 at MIT Engineering Systems Symposium

Zhang L, Levinson D (2005) The economics of transportation network growth. In: Milln PC, Inglada V (eds) Essays in transportation economics. Springer 